\title{
A case report of an unusual non-mucinous papillary variant of CPAM type 1 with KRAS mutations
}

\author{
Timco Koopman ${ }^{1,2^{*}} \mathbb{D}$, Bart L. Rottier ${ }^{3}$, Arja ter Elst ${ }^{2}$ and Wim Timens $^{2}$
}

\begin{abstract}
Background: congenital pulmonary airway malformation (CPAM) is the most frequent congenital lung disorder. CPAM type 1 is the most common subtype, typically having a cystic radiological and histological appearance. Mucinous clusters in CPAM type 1 have been identified as premalignant precursors for mucinous adenocarcinoma. These mucinous adenocarcinomas and the mucinous clusters in CPAM commonly harbor a specific KRAS mutation.

Case presentation: we present a case of a 6-weeks-old girl with CPAM type 1 where evaluation after lobectomy revealed a highly unusual complex non-mucinous papillary architecture in all cystic parts, in which both mucinous clusters and non-mucinous papillary areas harbored the known KRAS mutation.

Conclusions: we found that a KRAS mutation thought to be premalignant in mucinous clusters only, was also present in the other cyst lining epithelial cells of this unusual non-mucinous papillary variant of CPAM type 1, warranting clinical follow-up because of uncertain malignant potential.
\end{abstract}

Keywords: Congenital pulmonary airway malformation (CPAM), Congenital lung disorder, Mucinous adenocarcinoma, KRAS mutation

\section{Background}

Congenital pulmonary airway malformation (CPAM) is the most frequent congenital lung disorder. Of the five subtypes, CPAM type 1 is the most common. CPAM type 1 typically has a cystic radiological and histological appearance. Because of lung infection risk, CPAMafflicted lobes are surgically removed after birth. Additionally, microscopic mucinous clusters have been identified as premalignant precursors for mucinous adenocarcinoma. These mucinous adenocarcinomas and the mucinous clusters in CPAM commonly harbor a specific KRAS mutation. We present a case of CPAM type 1 with a highly unusual complex non-mucinous papillary architecture, in which both mucinous clusters

\footnotetext{
* Correspondence: t.koopman@umcg.nl

${ }^{1}$ Department of Pathology, Pathologie Friesland, Leeuwarden, The Netherlands

${ }^{2}$ Department of Pathology and Medical Biology, University of Groningen, University Medical Center Groningen, Groningen, The Netherlands Full list of author information is available at the end of the article
}

and non-mucinous papillary areas harbored the known KRAS mutation.

\section{Case presentation}

\section{Clinical presentation}

On the regular 20-week fetal anomaly ultrasound of a female infant, a macrocystic pulmonary malformation of the right lung was found, interpreted as likely congenital pulmonary airway malformation (CPAM). At $23+4$ weeks of gestation, placement of a shunt was indicated because of a mediastinal shift. Decompression of the left lung was achieved by a shunt in the cysts draining into the amnion. The infant was born spontaneously after $30+1$ weeks of gestation, with a birthweight of $1.6 \mathrm{~kg}$. At birth, the shunt was dislocated and being cyanotic and bradycardic the girl had to be mechanically ventilated. Initially this was successful, but after six hours chest drainage was indicated again. Four days later the CT-scan showed a multicystic malformation in the right lower lobe, in line with the initial suspicion of CPAM, without abnormal vascular supply. X-rays and CT scans are shown in Fig. 1. Six weeks after birth, when the

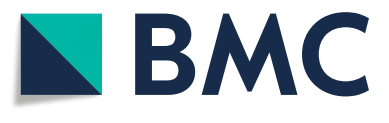

(c) The Author(s). 2020 Open Access This article is distributed under the terms of the Creative Commons Attribution 4.0 International License (http://creativecommons.org/licenses/by/4.0/), which permits unrestricted use, distribution, and reproduction in any medium, provided you give appropriate credit to the original author(s) and the source, provide a link to the Creative Commons license, and indicate if changes were made. The Creative Commons Public Domain Dedication waiver (http://creativecommons.org/publicdomain/zero/1.0/) applies to the data made available in this article, unless otherwise stated. 
infant reached the weight of two kilograms, lobectomy of the affected lobe was performed.

\section{Pathology}

The pathology findings are shown in Fig. 2. Gross examination showed a cystic lobe with multiple cysts larger than $2 \mathrm{~cm}$, the largest more than $3 \mathrm{~cm}$. Microscopic evaluation revealed cysts consistently lined with numerous complex non-mucinous papillary projections, lined with uniform non-ciliated cuboidal to low-columnar epithelium with immature morphology and without cytonuclear atypia, but without ciliated bronchial type epithelial cells. Immunohistochemistry showed diffuse strong positivity of TTF-1 (Thyroid Transcription Factor-1) and Napsin A in the epithelial cells of the papillary structures. Several interspersed small mucinous Periodic Acid Schiff stain (PAS) positive clusters were identified throughout the lesion. Additionally, the PAS stain showed glycogenosis in the alveolar septa in the non-involved part of the lobe, consistent with (variable or possibly resolving) pulmonary interstitial glycogenosis, which can be seen in relatively immature lung tissue [1]. No morphological atypical or malignant foci were found. The lesion was classified as a papillary variant of CPAM type 1 because of the size of the cysts and the architecture of the cyst wall with presence of a smooth muscle layer, with the notion of the unusual nonmucinous papillary morphology.

\section{Molecular analysis}

Molecular analysis was performed on three carefully selected areas: firstly the mucinous clusters, secondly the papillary areas and thirdly the pre-existent normal appearing lung. These areas were manually annotated by the pathologist on the corresponding Hematoxylin and Eosin (H\&E) slides, to ensure that the right areas were sampled for molecular analysis. DNA extracted (COBAS FFPE preparation kit, Roche) from Formalinfixed, Paraffin-embedded (FFPE) material of the three selected areas was sequenced with Next Generation Sequencing (NGS). Library preparation was performed using a custom Ampliseq panel, which included the hotspots of KRAS (codon 12, 13, 61, 117 and 146). The library was sequenced on an Ion Personal Genome Machine $^{\mathrm{Tm}}\left(\mathrm{PGM}^{\mathrm{Tm}}\right)$ System (Ion Torrent $\left.{ }^{\mathrm{Tm}}\right)$. Analysis of the NGS data was performed with JSI Nextseq software (JSI medical systems). Sequencing showed a KRAS: c.35G > A p.(G12D) mutation in the mucinous areas $(20 \%$ neoplastic cells, variant allele frequency $32 \%)$ as well as in the papillary areas $(80 \%$ neoplastic cells, variant allele frequency $20 \%$ ). To verify the absence of the KRAS mutation in normal appearing lung, a ddPCR using the KRAS screening assay $\left(\right.$ ddPCR $^{\mathrm{mi}} \quad$ KRAS G12/G13 Screening Kit \#1863506, Biorad) was performed. The KRAS mutation was not present in normal appearing lung (limit of detection $2 \%$ ).
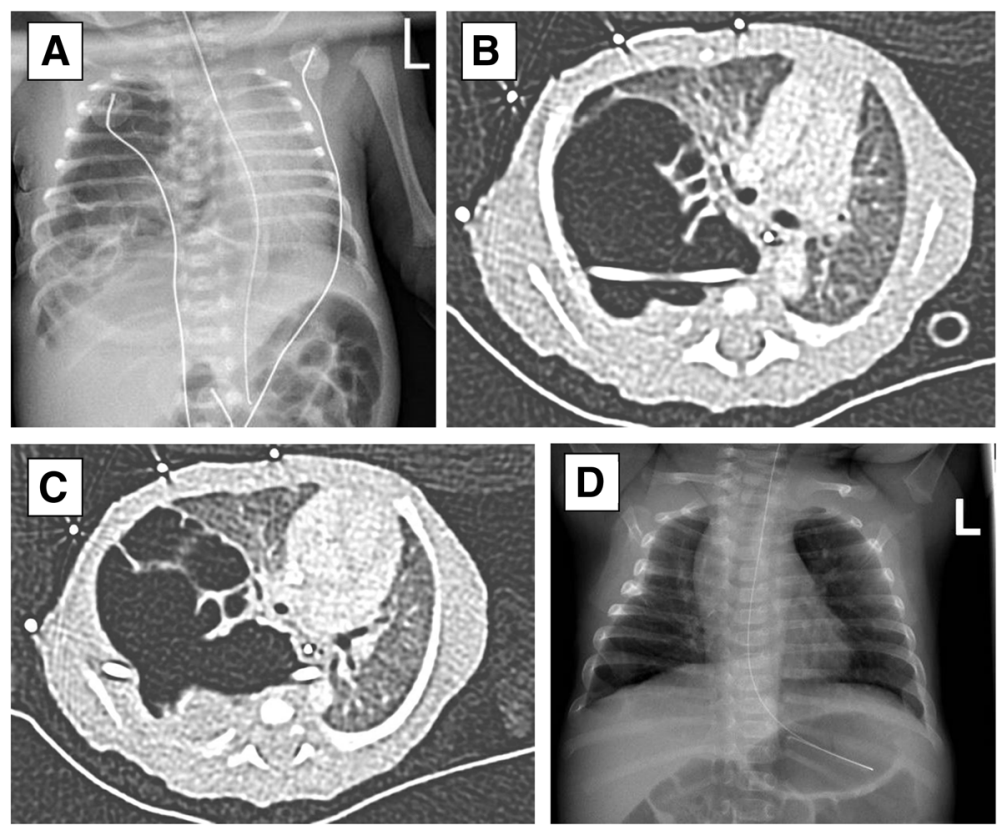

Fig. 1 Chest X-ray after initial stabilization on the NICU ward a showed a large right lung with cyst-like appearance and a mediastinal shift to the left. High resolution chest CT scans $\mathbf{b}$ and $\mathbf{c}$ showed a thick walled multicystic air filled process with a left-sided mediastinal shift. The chest drain can be seen. Chest $\mathbf{X}$-ray at the age of three months $\mathbf{d}$ showed slight post-operative thoracic cage deformity on the right, a clip in the right hilum, and normal aeration of both the right and the left lung 


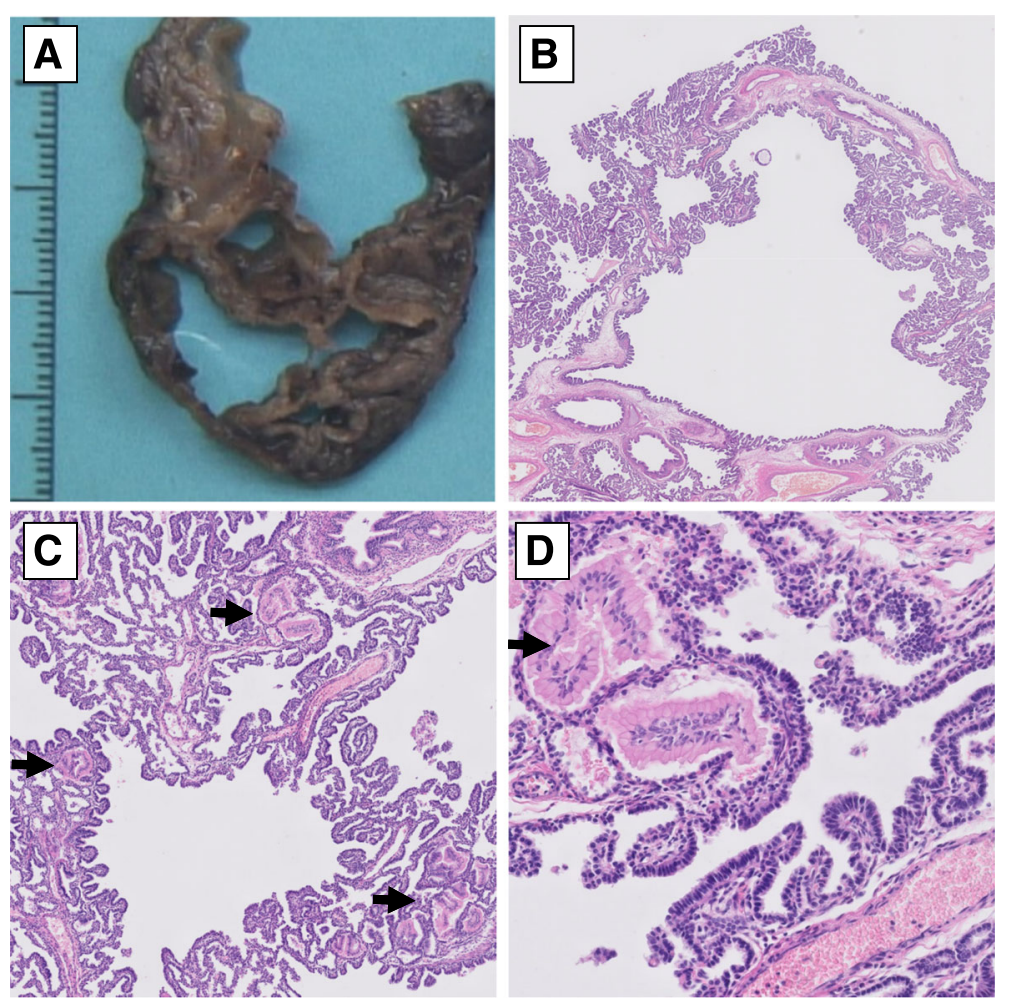

Fig. 2 Gross examination showed a cystic lung a, with numerous complex non-mucinous papillary projections on histologic evaluation b-d Numerous mucinous clusters were identified $\mathbf{c}$ and $\mathbf{d}$, arrows. Both these mucinous clusters as well as the papillary areas harbored KRAS c.35G > A mutations. Histology images at 10x b, 50x c and 200x d magnification

\section{Follow-up}

After surgery there were no per-operative or postoperative complications. Post-operative control X-rays showed a cystic residue, for which follow-up was indicated. During follow-up at the age of 6 months the child was thriving. In a multidisciplinary setting it was agreed upon that based on the potential pathogenicity of the mutations and the fact that the affected lung tissue was completely removed, high resolution chest CT scans will be performed at the ages of 1 and 3 years (arbitrarily chosen), combined with clinical follow-up.

\section{Discussion and conclusions}

A congenital thoracic malformation (CTM), postnatally diagnosed as a congenital pulmonary airway malformation (CPAM) and formerly called congenital cystic adenomatoid malformation (CCAM), is the most frequent congenital disorder of the lung accounting for $25 \%$ of all congenital lung disorders [2]. EUROCAT data report a prevalence of 1.05 per 10,000 pregnancies [3]. There are five subtypes of CPAM, depending on typical clinical and histological features [2, 4]. CPAM type 1 occurs most frequently $(60-70 \%$ of cases) and presents as one or more medium to large cysts measuring more than 2 $\mathrm{cm}$, usually limited to one lobe (95\%). It is primarily diagnosed in the first month of life. Because of the risk of lung infections, CPAM-afflicted lobes are surgically removed after birth. Histologic examination typically shows thin-walled cysts lined with ciliated pseudostratified columnar epithelium [2]. These cysts can have polypoid folds [5]. In the present case, histology revealed a highly unusual complex non-mucinous papillary architecture in which the papillary projections were not lined with bronchial epithelial ciliated cells as usual. To date, this has not been described in literature. Fisher et al. described a CPAM type 1 case with papillary architecture [6]. However, they found large papillary projections in an otherwise conventional CPAM and not the complex papillary morphology as seen in the current case.

The use of elective surgery in non-respiratory compromised children remains controversial [7]. Long-term survival after surgical removal of CPAM afflicted lobes is usually very good. However, CPAM type 1 has been associated with the development of mucinous adenocarcinoma (formerly called mucinous bronchioloalveolar carcinoma) [4, 5]. Mucinous clusters are present in one third of CPAM type 1 cases and have been identified as premalignant precursors for mucinous adenocarcinoma, although the occurrence of carcinomatous transformation is only $<1 \%[5,8,9]$. In mucinous adenocarcinoma 
a specific KRAS mutation is found: KRAS c.35G > A, p.(G12D) [10]. This KRAS mutation has also been found in the mucinous clusters in CPAM [11], possibly being premalignant precursors, and was also present our case. Remarkably, the KRAS c35G > A mutation was also found in the other, histologically benign appearing, nonmucinous papillary areas. The clinical relevance of the presence of this mutation in this setting is unclear, but is likely also to be considered as indicating potential malignancy.

In conclusion, we present a case of a 6-weeks-old girl where lobectomy showed a CPAM type 1-like cystic lesion with a highly unusual papillary morphology, in which both mucinous clusters as well as non-mucinous papillary areas harbored a KRAS c.35G > A mutation, in adults known to be associated with adenocarcinoma. Importantly, we found that a KRAS mutation thought to be premalignant in mucinous clusters only, was also present in the other cyst lining epithelial cells of this unusual non-mucinous papillary variant of CPAM type 1 , warranting clinical follow-up because of uncertain malignant potential.

\section{Abbreviations}

CCAM: Congenital cystic adenomatoid malformation; CPAM: Congenital pulmonary airway malformation; CTM: Congenital thoracic malformation; FFPE: Formalin-fixed, Paraffin-embedded; PAS: Periodic acid schiff; TTF-

1: Thyroid transcription factor 1

\section{Acknowledgements}

We thank Professor Andrew Nicholson, Brompton Hospital, London, UK for his valuable advice on this case. We thank M.V. Verhagen, radiologist of the University Medical Center Groningen, for his help acquiring the CT scan images.

\section{Authors' contributions}

TK wrote the manuscript and was the Resident in Pathology involved in the case. BLR helped writing the manuscript, especially the clinical presentation including Fig. 1, as the Pediatrician involved in the case. AtE helped writing the manuscript, especially the molecular analysis, and conducted the molecular analysis, as the Clinical Molecular Biologist involved in the case. WT supervised and revised the manuscript and was the senior Pathologist involved in the case. All authors have read and approved the final manuscript.

\section{Funding}

This study was not funded.

\section{Availability of data and materials}

All data generated or analyzed during this study are included in this published article.

\section{Ethics approval and consent to participate}

The article describes a case report. Therefore, no additional permission from our Ethics Committee was required. The parents of the patient have given written consent for publication.

\section{Consent for publication}

The parents of the patient have given written consent for publication.

\section{Competing interests}

The authors declare that they have no competing interests.

\section{Author details}

'Department of Pathology, Pathologie Friesland, Leeuwarden, The Netherlands. ${ }^{2}$ Department of Pathology and Medical Biology, University of Groningen, University Medical Center Groningen, Groningen, The Netherlands. ${ }^{3}$ Department of Pediatrics, University of Groningen, University Medical Center Groningen, Groningen, The Netherlands.

Received: 22 August 2019 Accepted: 17 February 2020

Published online: 24 February 2020

\section{References}

1. Dishop MK, Langston C. Chapter 2: progress in the pathology of diffuse lung disease in infancy: changing concepts and diagnostic challenges. In: Timens W, Popper HH, editors. Pathology of the Lung, Volume 12, Monograph 39. United Kingdom: European Respiratory Society Journals Ltd; 2007. p. 21-36.

2. Stocker JT, Drake RM, Madewell JE. Cystic and congenital lung disease in the newborn. In: Rosenberg HS, Boland RP, editors. Perspectives in pediatric pathology. New York: Year Book Medical Publishers; 1978. p. 93-154.

3. EUROCAT, European Platform on Rare Disease Registration. Prevalence charts and tables. 2019. https://eu-rd-platform.jrc.ec.europa.eu/eurocat/ eurocat-data/prevalence en. Accessed 22 Feb 2020.

4. Stocker JT, Husain AN. Chapter 1: Cystic lesions of the lung in children: classification and controversies. In: Timens W, Popper HH, editors. Pathology of the Lung, Volume 12, Monograph 39. United Kingdom: European Respiratory Society Journals Ltd; 2007. p. 1-20.

5. MacSweeney F, Papagiannopoulos K, Goldstraw P, Sheppard MN, Corrin B, Nicholson AG. An assessment of the expanded classification of congenital cystic adenomatoid malformations and their relationship to malignant transformation. Am J Surg Pathol. 2003;27(8):1139-46.

6. Fisher JE, Nelson SJ, Allen JE, Holzman RS. Congenital cystic adenomatoid malformation of the lung. A unique variant. Am J Dis Child. 1982;136(12): 1071-4.

7. Peters RT, Burge DM, Marven SS. Congenital lung malformations: an ongoing controversy. Ann R Coll Surg Engl. 2013;95(2):144-7.

8. Ota H, Langston C, Honda T, Katsuyama T, Genta RM. Histochemical analysis of mucous cells of congenital adenomatoid malformation of the lung: insights into the carcinogenesis of pulmonary adenocarcinoma expressing gastric mucins. Am J Clin Pathol. 1998;110(4):450-5.

9. Stacher E, Ullmann R, Halbwedl I, Gogg-Kammerer M, Boccon-Gibod L, Nicholson AG, et al. Atypical goblet cell hyperplasia in congenital cystic adenomatoid malformation as a possible preneoplasia for pulmonary adenocarcinoma in childhood: a genetic analysis. Hum Pathol. 2004;35(5): $565-70$

10. Marchetti A, Buttitta F, Pellegrini S, Chella A, Bertacca G, Filardo A, et al. Bronchioloalveolar lung carcinomas: K-ras mutations are constant events in the mucinous subtype. J Pathol. 1996;179(3):254-9.

11. Lantuejoul S, Nicholson AG, Sartori G, Piolat C, Danel C, Brabencova E, et al. Mucinous cells in type 1 pulmonary congenital cystic adenomatoid malformation as mucinous bronchioloalveolar carcinoma precursors. Am J Surg Pathol. 2007;31(6):961-9.

\section{Publisher's Note}

Springer Nature remains neutral with regard to jurisdictional claims in published maps and institutional affiliations.

\section{Ready to submit your research? Choose BMC and benefit from:}

- fast, convenient online submission

- thorough peer review by experienced researchers in your field

- rapid publication on acceptance

- support for research data, including large and complex data types

- gold Open Access which fosters wider collaboration and increased citations

- maximum visibility for your research: over $100 \mathrm{M}$ website views per year

At $\mathrm{BMC}$, research is always in progress.

Learn more biomedcentral.com/submission 